\title{
Hedging in spoken conversations by Norwegian learners of English
}

\author{
Stine Hulleberg Johansen \\ University of Oslo \\ s.h.johansen@ilos.uio.no
}

\begin{abstract}
Hedging is an important aspect of pragmatic competence, but it is also a complex phenomenon that is difficult to master. This has resulted in underuse of hedging strategies by language learners, and many learners limit their hedging repertoire to a few strategies. This study compares the use of 10 hedging expressions commonly used in informal spoken English, a bit, I mean, I think, just, kind of/kinda, like, might, probably, thing(s), and you know, in data from LINDSEIno, a corpus of Norwegian advanced learners, and LOCNEC, a comparable corpus of native English speakers. Norwegian learners typically show a high level of grammatical competence, but research on their pragmatic competence is limited. This study adds to the empirical research on Norwegian advanced learners by comparing the use of these expressions in native and learner language. The results indicate that as a group, Norwegian learners underuse hedging strategies, but when each expression and individual variation are considered, the picture is more nuanced. In fact, several of the Norwegian learners' hedging practices partially overlap with several of the native speakers' practices concerning hedging frequency and types of hedging strategies used.
\end{abstract}

Keywords: Hedging, Learner Corpus Research, Norwegian Learners, Corpus Pragmatics 


\section{Introduction}

Norwegian learners generally perform well on European language tests measuring various aspects of grammatical competence $;{ }^{1}$ however, less is known about their pragmatic competence. Learners' grammatical and pragmatic competence tends to develop unevenly (Romero-Trillo, $2002,70)$. Whereas acquiring pragmatic competence in one's first language is "an unconscious process which co-occurs with socialisation and acculturation into the community into which one is born" (Holmes et al., 2020, 1), learners in a non-target environment acquire the target language asynchronously through formal instruction. However, as pragmatic competence is difficult to integrate in educational syllabi, it is not always given the attention it deserves in second- and foreign-language teaching. Language learners may therefore produce "grammatically flawless speech that nonetheless fails to achieve its communicative aims" (Fraser, 2010, 15). The higher the level of fluency, the greater the risk of communicative failure due to the underlying expectation that non-native speakers who master the target language on the surface, also master that language's underlying social conventions (Nikula, 1997, 188-189).

This study investigates hedging, a complex aspect of pragmatic competence that may cause problems for language learners. Hedging may be defined as discourse strategies that attenuate the force, truth, or effects on the hearer (Hyland, 1996, 1998; Kaltenböck et al., 2010) and may be realised through nearly any linguistic form. As with many pragmatic features, these forms often do not correspond across languages (Romero-Trillo, 2018), and such cross-linguistic differences may lead learners to favour certain pragmatic expressions. Several studies of learners with various first languages (L1s) have demonstrated the over- and underuse of different hedging expressions (e.g. Nikula, 1997). Moreover, previous research on hedging by lower secondary school Norwegian learners showed that learners use fewer hedging strategies than their native English counterparts and exhibit less variation in their hedging repertoires (Hasselgreen, 2004). Still, Norwegian learners' hedging strategies remain under-researched. To date, there are no

\footnotetext{
${ }^{1}$ E.g. “Assessment of English,” 2004, https://www.udir.no/eksamen-og-prover/prover/nasjonale-prover/, and "EF English Proficiency Index," 2019, https://www.ef.com/wwen/epi/.
} 
corpus-based studies devoted primarily to hedging in spoken English by Norwegian advanced learners.

Previous comparative studies of learner and native varieties have been criticised for focusing on frequencies as the only diagnostic of importance (Paquot \& Plonsky, 2017) and for assuming the homogeneity of non-native and native speaker groups (Gablasova et al., 2017). Thus, studies are needed that nuance observed differences at the group level by looking at dispersion (Gries, 2008).

This study aims to strengthen the empirical research on hedging by studying 10 hedging expressions, some of which have never been investigated before, in Norwegian advanced learners' spoken English. The investigation concerns the use of a bit, I mean, I think, just, kind of/kinda, like, might, probably, thing(s), and you know in data from the Norwegian Louvain International Database of Spoken English Interlanguage (LINDSEI-no) ${ }^{2}$ and the comparable Louvain Corpus of Native English Conversation (LOCNEC) (De Cock, 2004). ${ }^{3}$ The forms are chosen based on the results of a contrastive study of hedging strategies in Norwegian and English (Johansen, 2020). Inter- and intraspeaker variation are considered to see whether Norwegian advanced learners show signs of underuse (Granger, 2015), as observed in studies of lowerproficiency learners, or whether their use of hedging strategies is similar to that of native speakers. Specifically, the study tackles the following research questions:

RQ1: Do Norwegian advanced learners use fewer instances of hedging strategies (tokens) than native English speakers?

RQ2: Do Norwegian advanced learners use a more limited range of expressions (types) than native English speakers?

Section 2 of this paper outlines developments in hedging research and presents studies of hedging in learner language. Section 3 describes the materials and methods. Section 4 presents and discusses the results, and section 5 offers concluding remarks.

\footnotetext{
${ }^{2}$ https://app.cristin.no/projects/show.jsf?id=404547, https://uclouvain.be/fr/node/11968

${ }^{3}$ https://uclouvain.be/fr/node/11973
} 


\section{Hedging as an aspect of pragmatic competence}

Pragmatic competence has been described as "the linguistic ability to communicate your intended message with all its nuances in any socio-cultural context and to interpret the message of your interlocutor as it was intended" (Fraser, 2010,15). Mastering hedging is merely one aspect of this competence. Nevertheless, hedging is critical for communication success (Fraser, 2010, 15). Hedges allow the speaker to tone down a potentially face-threatening proposition through expressions of tentativeness or possibility and to avoid sounding too categorical by minimising commitment to a proposition. Hedging may also mitigate negative effects on the hearer (Hyland, 1998, 177). Hedging strategies may have a propositional scope, affecting the content of the proposition, as exemplified in (1). They may also say something about the relationship between the speaker and the proposition (speaker-oriented), as in (2), or affect the relationship between the speaker and the hearer (hearer-oriented), as in (3).

(1) I kind of changed my mind (LOCNEC EN0029)

(2) I think it was in Berlin or somewhere (LOCNEC EN009)

(3) $[\ldots]$ it depends how good it is you know (LOCNEC EN0022)

Research on hedging in English interlanguage is relatively limited compared to that in native English (Neary-Sundquist, 2013, 153), and as with most corpus linguistic studies, studies on written language outnumber those on spoken language (Adolphs \& Carter, 2013, 1). Overall, studies on hedging in written learner language show that learners tend to use a limited range of hedging strategies and fewer strategies than native speakers. For example, Ventola and Mauranen (1990) found that Finnish learners used a limited range of hedging expressions in academic writing. In a study of indirectness in academic writing, Hinkel (1997) found that Chinese, Korean, Japanese, and Indonesian learners used certain hedges more frequently than native speakers of English but did not use other indirectness devices. A study of English papers by Lithuanian undergraduate students showed that learners preferred the modal verb can over other hedging strategies (Šeškauskienè, 2008). 
Studies of hedging in spoken learner English generally support the tendencies indicated by studies of hedging in learner writing. For example, Kasper (1979) studied German learners' use of hedging strategies and found that modality is present in speaker planning but not necessarily in speaker production. Kärkkäinen (1990) compared the use of epistemic modality expressions among Finnish learners and native speakers of English and discovered that the learners used fewer hedging strategies and had less variation in their repertoire than native English speakers. The results also indicated that the limited use of strategies was not necessarily a result of sociopragmatic transfer, as the Finnish learners frequently used hedging strategies when speaking Finnish. Nikula (1997) also studied hedging in spoken English by Finnish learners and found that they used fewer strategies than native English speakers. In a recent study of hedging strategies in learner and teacher talk in a classroom setting, Friginal, Lee, Polat, and Roberson (2017) found that L2 speakers of English only used 20 out of 102 potential hedging expressions examined, whereas the teachers, with English as their L1, used about half.

Studies of hedging by Norwegian learners are relatively scarce, particularly of spoken interlanguage. However, the studies that exist indicate that Norwegian learners generally underuse hedging expressions in English. The perhaps most elaborate study of Norwegian learners, Hasselgreen's (2004), compared the use of eight expressions (I think, like, sort of/kind of, a bit, just, or something, not really, and and everything/that/stuff/things) in Norwegian lower secondary school learners and native English speakers (Hasselgreen, 2004, 205). The comparison showed that the number of tokens was generally lower among the Norwegian learners, and I think emerged as the learners' preferred hedging strategy. In an unpublished master's thesis, Sandal $(2016,116)$ reported a general underrepresentation of the discourse marker use of like, well, and you know among Norwegian advanced learners of English. However, Sandal looked at pragmatic functions beyond those of hedging.

Most studies of hedging in written discourse by Norwegian learners only discuss hedging as one of several pragmatic functions of particular expressions, e.g. Hasselgård \& Johansson's (2011) discussion of seem. Thomson (2016) studied hedging strategies in written English by Norwegian lower secondary school pupils and found that the pupils had a good 
understanding of hedging devices but used a limited range of hedging expressions. The results also showed significant individual variation among pupils in the use of hedging strategies.

Despite these studies, hedging by Norwegian learners remains under-researched, and more research is needed to better understand the hedging competence of Norwegian advanced learners of English. The study proposed here contributes to this research. The study aims to investigate the extent to which advanced learners still underuse hedging expressions, as pupils in lower secondary school have been found to do, the extent to which this is true for individual expressions, and whether the learners use a narrower range of expressions than native speakers.

\section{Materials and methods}

\subsection{Materials}

The 10 forms investigated here come from a previous study of hedging strategies in informal conversations using data from the spoken British National Corpus 2014 (Johansen, 2020; Love et al., 2017). Through a partly bottom-up approach, the previous study retrieved 715 hedging strategies, and the 10 proportionally most frequent forms among these strategies serve as the starting point for this study. The forms investigated are a bit, I mean, I think, just, kind of/kinda, like, might, probably, thing (s), and you know.

To investigate Norwegian learners' hedging in spoken English, data from the Norwegian LINDSEI corpus, LINDSEI-no, was used. LINDSEI, one of the most recognised learner corpora (Romero-Trillo, 2018, 115), was created for systematically studying the spoken English of learners with different L1s. The corpus consists of spoken discourse produced by university undergraduates and learners of English with an advanced proficiency level (Gilquin et al., 2010, 7). LINDSEI-no was not part of the original corpus launched in 1995 but was compiled following the same format by Inland Norway University of Applied Sciences between 2010 and 2015. The LINDSEI-no data is compared to data from the comparable LOCNEC corpus of native-speaker English.

The LINDSEI and LOCNEC corpora consist of informal interviews. Each interview includes three speech tasks, of which a free informal discussion is considered the main part 
(Gilquin et al., 2010, 3). This study uses only this free discussion part because it was considered most similar to authentic conversation, the "genre" from which the expressions investigated were drawn, and it restricts the material to a single type of interactional context. Only the learners' utterances are included. Table 1 presents the number of words in the sample.

Table 1 No. of words in the corpora and sample

\begin{tabular}{ll|l|l} 
& $\begin{array}{l}\text { Total no. of words } \\
\text { of learner language }\end{array}$ & $\begin{array}{l}\text { Total no. of words in } \\
\text { free discussion } \\
\text { (tokens) }\end{array}$ & $\begin{array}{l}\text { Total no. of } \\
\text { speakers }\end{array}$ \\
\hline LINDSEI-NO & 122,956 & 43,431 & 50 \\
LOCNEC & 126,666 & 70,957 & 50
\end{tabular}

\subsection{Methods}

The corpus data was analysed using WordSmith 7 following the form-to-function approach commonly applied in corpus pragmatic studies. This approach uses previously identified constructions as the starting point for the study and examines their potential pragmatic functions in natural text (Aijmer \& Rühlemann, 2015). All instances of the chosen words were read vertically using the keyword in context function, and all canonical uses were removed. The pragmatic uses were investigated more carefully to determine whether they were used as hedges or for other purposes. When it was difficult to determine whether a word was used as a hedge, more context was consulted.

An inclusive approach was chosen with respect to what was considered a hedge. Many of these words serve multiple pragmatic functions simultaneously, and it is often difficult to determine a word's exact function(s), even in context. When a word's function was ambiguous, the word was included as a hedge in the analysis of both the learner and the native speaker data to ensure the validity of the comparison. Example (4) presents an ambiguous use of just. Pragmatic uses of just include both intensifying and toning-down uses. Furthermore, pragmatic just is also closely related to the canonical use in the sense of merely. Distinguishing between these uses is often difficult. 
(4) (erm) .. I don't find it very easy but I love the language [...] I loved it at school (erm) and I I get a real buzz out of speaking the language [...] or I did when I was well I did when I was in France but not when I'm in England it doesn't get you anywhere [...]

I just enjoyed it (LOCNEC EN0032)

Following the identification of the hedging uses, frequencies were compared across the two varieties using a log-likelihood test. ${ }^{4}$ However, corpus studies of learner language have been criticised for being too focused on frequency (Paquot \& Plonsky, 2017), which may be misleading when used as the only measure to describe the data (Gries, 2008, 404). Similarly, Gablasova et al. $(2017,133-135,137)$ argued that to make sound comparisons, interspeaker variation should also be considered. Considering interspeaker variation in addition to frequency is important not only for the study of learner language. It is equally important to look at interspeaker variation in L1 speakers, as they are not necessarily homogenous (Gablasova et al., 2017, 141). This study examined intra-speaker variation in both varieties.

\section{Results and discussion}

Of the 1,259 instances of the 10 expressions retrieved from LINDSEI-no, 853 were hedging uses. Of the 3,037 instances retrieved from LOCNEC, 2,357 were hedging uses. Table 2 presents the total number of hedging strategies per language variety and the frequencies for each form in each variety.

\footnotetext{
${ }^{4}$ http://ucrel.lancs.ac.uk/llwizard.html
} 
Table 2 Frequencies for all forms in both varieties

\begin{tabular}{lllllllll} 
& \multicolumn{3}{c}{ LINDSEI-NO } & \multicolumn{5}{c}{ LOCNEC } \\
\cline { 2 - 8 } & $\begin{array}{l}\text { Raw } \\
\text { freq. }\end{array}$ & $\begin{array}{l}\text { Freq. } \\
\text { per } \\
1,000 \\
\text { words }\end{array}$ & $\begin{array}{l}\text { \% of the } \\
\text { total no. } \\
\text { of } \\
\text { hedging } \\
\text { strategies }\end{array}$ & $\begin{array}{l}\text { Raw } \\
\text { freq. }\end{array}$ & $\begin{array}{l}\text { Freq. } \\
\text { per } \\
1,000 \\
\text { words }\end{array}$ & $\begin{array}{l}\text { \% of the } \\
\text { total no. } \\
\text { of } \\
\text { hedging } \\
\text { strategies }\end{array}$ & $\begin{array}{l}\text { Log } \\
\text { likelihood }\end{array}$ & p-value \\
\hline a bit & 50 & 1.2 & 5.9 & 121 & 1.71 & 5.1 & 5.74 & $p<0.05$ \\
I mean & 30 & 0.7 & 3.5 & 341 & 4.81 & 14.5 & 175.37 & $p<0.0001$ \\
I think & 148 & 3.4 & 17.4 & 263 & 3.71 & 11.2 & 0.67 & $\mathrm{NS}^{5}$ \\
just & 211 & 4.9 & 24.7 & 402 & 5.67 & 17.1 & 3.32 & $\mathrm{NS}$ \\
kind oflkinda & 65 & 1.5 & 7.6 & 38 & 0.54 & 1.6 & 26.56 & $p<0.0001$ \\
like & 142 & 3.3 & 16.6 & 438 & 6.2 & 18.6 & 47.71 & $p<0.0001$ \\
might & 17 & 0.4 & 2.0 & 43 & 0.6 & 1.8 & 2.46 & $\mathrm{NS}$ \\
probably & 38 & 0.9 & 4.5 & 68 & 1.0 & 2.9 & 0.20 & $\mathrm{NS}$ \\
thing(s) & 89 & 2.1 & 10.4 & 240 & 3.4 & 10.2 & 17.47 & $p<0.0001$ \\
you know & 53 & 1.2 & 6.2 & 403 & 5.7 & 17.1 & 159.82 & $p<0.0001$ \\
\hline Total & 853 & & $\approx 100$ & 2,357 & & $\approx 100$ & 186.20 & $p<0.0001$
\end{tabular}

\subsection{Do Norwegian advanced learners use fewer instances of hedging strategies (tokens) than native English speakers?}

Overall, at a group level, Norwegian learners hedged less often than native English speakers did. As can be seen from Table 2, the total number of hedging strategies was significantly higher for native speakers than for learners $(\mathrm{p}<0.0001)$, indicating an underuse of hedging strategies by Norwegian learners. This result is in line with the expectations outlined in section 1 and corroborates previous research on learners in general and Norwegian leaners in particular. For example, Nikula (1997) found that Finnish learners of English hedged less often than native English speakers. Similarly, Hasselgreen (2004) found that Norwegian learners generally used fewer instances of hedging strategies than their native English counterparts. However, Hasselgreen (2004) studied learners at the lower secondary school level; thus, the data is not directly comparable to that of the current study. The results are also in line with those of Sandal (2016), who discovered an underrepresentation of all pragmatic uses of like and you know by

${ }^{5}$ Not significant 
Norwegian advanced learners. As shown below, cross-linguistic influence from the Norwegian learners' L1 may help explain this pattern.

However, if we look at individual expressions presented in Table 2, we have to nuance our claim about underuse. Although five out of 10 expressions (a bit, I mean, like, thing(s), and you know) are underused, there is no statistically significant difference for four of the expressions (I think, just, might, and probably), and in one case (kind of), the data actually show overuse by the Norwegians. A bit, might and probably were relatively infrequent in both corpora and will not be further commented on.

Like is used significantly more by native speakers of English, but it is also frequently used among the Norwegian learners. This might be because several of the pragmatic functions of like have been found to overlap with the Norwegian liksom ('like') (Hasund, 2003), which is frequently used in Norwegian informal speech. However, there is no one-to-one correspondence between like and liksom, and it may be the case that Norwegian learners do not know the full range of functions of the English like, and how they differ from those of liksom. $\operatorname{Thing}(s)$ was also used more frequently by native speakers than learners. Many of the occurrences of thing $(s)$ were in the form of the general extender and things. In the results of Hasselgreen (2004), general extenders such as and things/stuff were used less frequently by Norwegian learners than native speakers.

Among the hedging strategies where the non-native and native use diverge, the biggest difference is found in the use of you know and I mean. Previous research has indicated that learners prefer explicit hedging strategies, those that refer explicitly to the speaker (or hearer) (Nikula, 1997) and automatically introduce "an explicit argumentative perspective to the discourse" (Baumgarten \& House, 2010, 1185). As you know and I mean are examples of explicit strategies, we might have expected Norwegian learners to prefer such expressions.

A potential explanation for the low number of you know and I mean in the Norwegian learner data could be that the direct translations of these two expressions into Norwegian $\mathrm{du}$ vet/vet du ('you know', 'know you') and jeg mener ('I mean'), although they can be used to hedge, have not undergone the same pragmaticalisation process as you know and I mean in English (Aijmer, $1997,2)$ and thus are not used to the same extent in Norwegian (Johansen, 2020). Norwegian 
learners may transfer the conventions of use for these strategies into English, which could explain the underrepresentation of you know and I mean. Furthermore, the modest number of occurrences of you know among the Norwegian learners may also relate to the mismatch in form between you know and the Norwegian pragmatic particle jo ('of course', 'after all'), although jo shares many pragmatic functions with you know, such as signalling that the information in the proposition is given or shared by the interlocutors. Jo does not have a direct translation into English, and advanced learners might be unaware of this overlap in functions between jo and you know and therefore not use you know in some situations where they would have used jo. Jo is frequent in Norwegian informal speech (Berthelin \& Borthen, 2019, 1), but you know is underrepresented in English by Norwegian learners.

Among the hedging strategies for which there was no statistical difference between L1 and L2, I think and just were the most frequently used. Previous research on I think in native English has shown that it is "almost ubiquitous" as a stance-marker in spoken L1 English (Baumgarten \& House, 2010, 1186). Influence from English may be a reason for the high I think use in the Norwegian learner data; however, frequency in input does not seem to be the only factor influencing Norwegian learners' performance. Otherwise, we might have expected a higher number of other frequently used expressions, such as you know and I mean, which are underrepresented. The relatively high occurrence of I think may be due to its close resemblance to the Norwegian expression jeg tror ('I think'), which is frequently used to express uncertainty in Norwegian. Thus, I think differs from I mean and you know. In addition to resembling the Norwegian uncertainty marker jeg tror, I think, like I mean and you know, is an explicit way of expressing uncertainty or lack of commitment to the proposition. By using I think, speakers express their feelings, attitudes, value judgements, and assessments towards the proposition in addition to the propositional content (Baumgarten \& House, 2010). Hasselgreen (2004, 208) suggests that the explicit nature of I think could be a reason for its frequent use by Norwegian learners.

The frequent use of just by Norwegian learners is in line with previous research on Norwegian learners. Hasselgreen (2004) reported that just is frequent among both Norwegian lower secondary school learners and English native speakers; just and I think are the two most 
favoured hedges among the learners in her data. One possible explanation for the frequent use of just in the Norwegian learner data could be that just is one of several translations of the Norwegian pragmatic marker bare ('just', 'merely'), which is frequently used in informal spoken discourse (Hasund et al., 2012; Opsahl \& Svennevig, 2007). Bare is used to express several pragmatic functions in Norwegian. When used as a hedge, bare reduces the speaker's commitment to the proposition and has a toning-down function (Hasund et al., 2012, 45). Transfer from Norwegian cannot easily explain the overuse found with kind of, the only form occurring more frequently among the Norwegian learners than among native speakers. (There were no instances of the contracted form kinda in either of the corpora.) Previous research on kind of has indicated that although kind of and sort of seem to have the same meaning (Kay, 1997, 151), kind of is not used to the same extent as sort of in British English (Aijmer, 2002, 207), which is the variety of the LOCNEC speakers. However, both kind of and sort of are more frequent in spoken discourse than in written discourse, and kind of is the more common of the two in spoken discourse (Gries \& David, 2007). Influence from spoken American English may thus be a reason for the frequent use of kind of by Norwegian learners. The English spoken by Norwegian learners is heavily influenced by American television and is often humorously characterised as being somewhere in the mid-Atlantic, meaning that Norwegian learners incorporate features from both American and British English.

The underuse by Norwegian learners illustrated in Table 2 becomes even more nuanced when we consider interspeaker variation. Figure 1 shows the total number of hedges (tokens) per speaker in both varieties. 


\section{Nordic Journal of Modern Language Methodology}

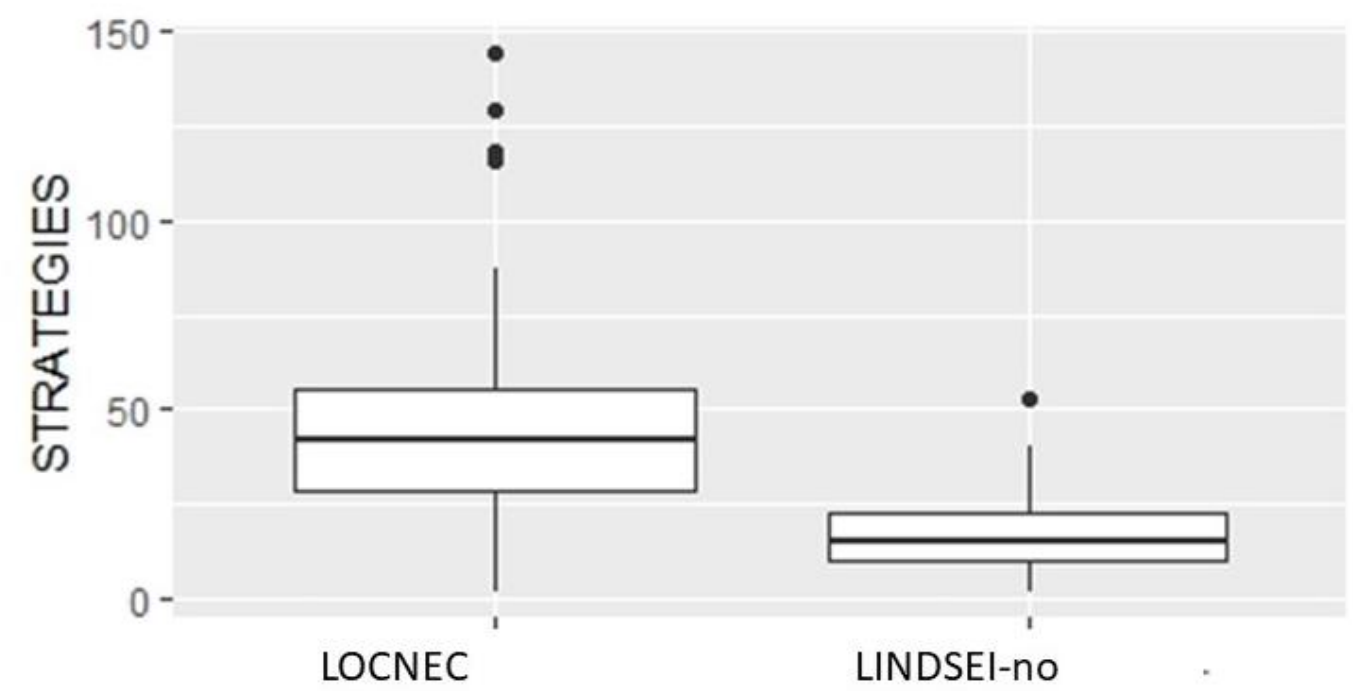

Figure 1 Total number of hedges (tokens) per speaker.

Although most Norwegian learners are outside the interquartile range of the native speaker data, $16 \%$ of the Norwegian learners (eight out of 50 speakers) are within the $75^{\text {th }}$ percentile of the native speakers. Furthermore, $18 \%$ of the native speakers (nine out of 50 speakers) use 22 or fewer strategies and thus resemble many of the Norwegian learners, indicating that a number of the Norwegian learners display a native-like frequency of hedging.

If we look at the dispersion of each hedging strategy (Figures 2 and 3), native speakers generally exhibit more variation than Norwegian learners. For the learners, most of the observations are concentrated at the lower end of the scale, and the medians are generally lower than for the native speakers. However, several native speakers are quite low on the scale, which means that the Norwegians are, to a large extent, within the range of native speakers. 


\section{Nordic Journal of Modern Language Methodology}

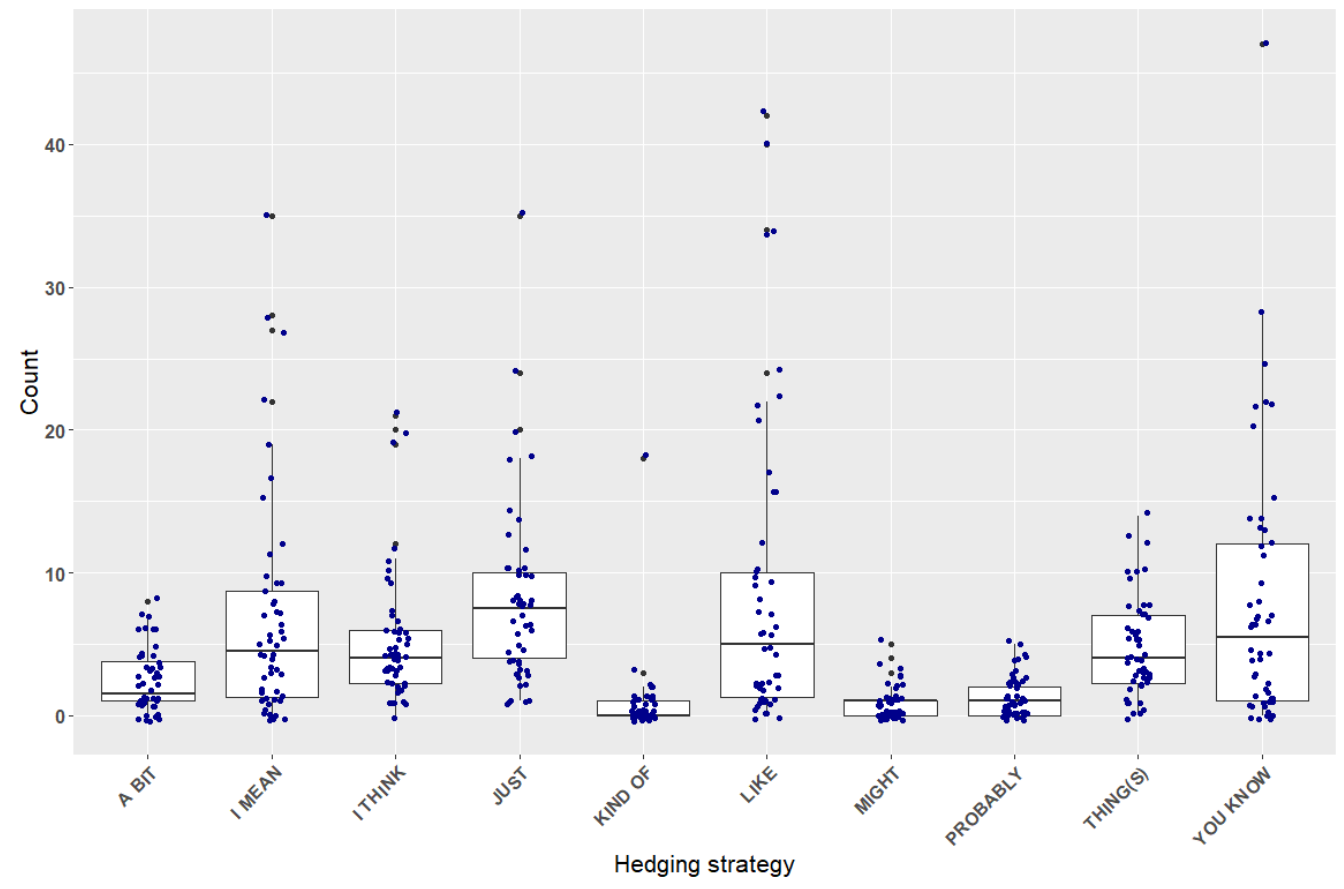

Figure 2 Individual variation per expression in LOCNEC.

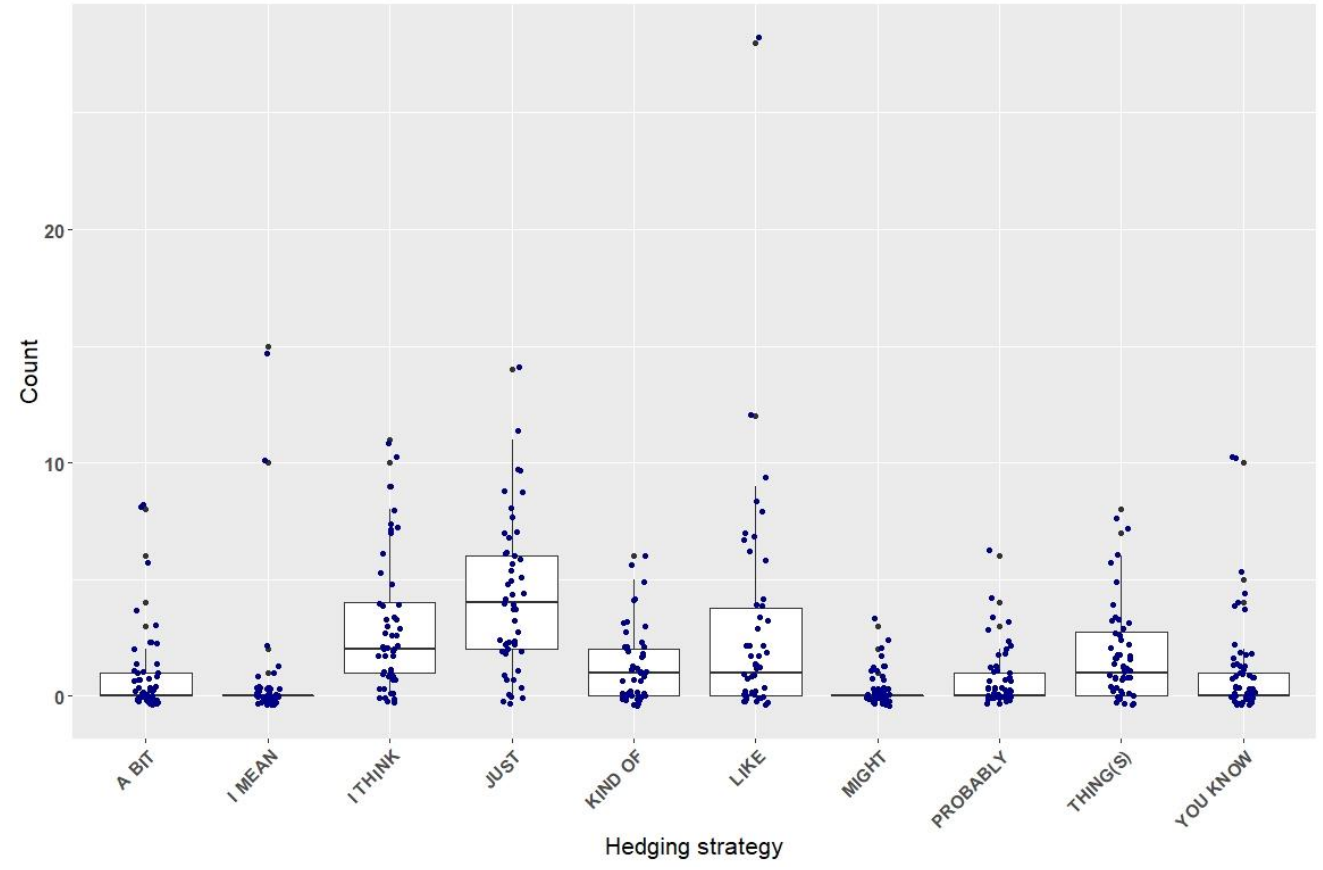

Figure 3 Individual variation per expression in LINDSEI-no. 
For eight out 10 expressions (a bit, I think, just, like, might, probably, thing(s), and you know) there is partial overlap between the first quartile in the native speaker data and the third quartile in the learner data, which means that some Norwegian learners are in fact within the native speaker range.

In summary, the total numbers at the group level indicate that Norwegian learners use fewer hedges than their native English counterparts. However, the total number per speaker and the total number of uses per word indicate that this statement needs to be modified. As illustrated in Figure 1, some native speakers use the same number of hedges as the Norwegians learners, although the majority tend to use more. Also, when we look at each individual expression, many native speakers use a similar number of hedges as the Norwegian learners.

\subsection{Do Norwegian advanced learners use a more limited range of expressions (types) than native English speakers?}

At the group level, both the native speakers and the learners used all 10 expressions. Therefore, we cannot claim that the learners exhibit a more restricted range than the native speakers. This contrasts with previous research on learners with different L1s. For example, Kärkkäinen’s (1990) study of Finnish learners showed that the learners exhibited limited variation when speaking English. Similarly, Friginal et al. (2017) found that language learners in a native environment used fewer hedging expressions than their teachers. However, the current study investigates only 10 expressions, so we must be careful when generalising from these results. If the full range of possible hedging expressions had been examined, the learners might have turned out to have a smaller repertoire.

Just like with instances of hedging, it is possible to look at the range of expressions at an individual level. Figure 4 shows the total number of hedging strategies (types) per speaker in LINDSEI-no and LOCNEC. 


\section{Nordic Journal of Modern Language Methodology}

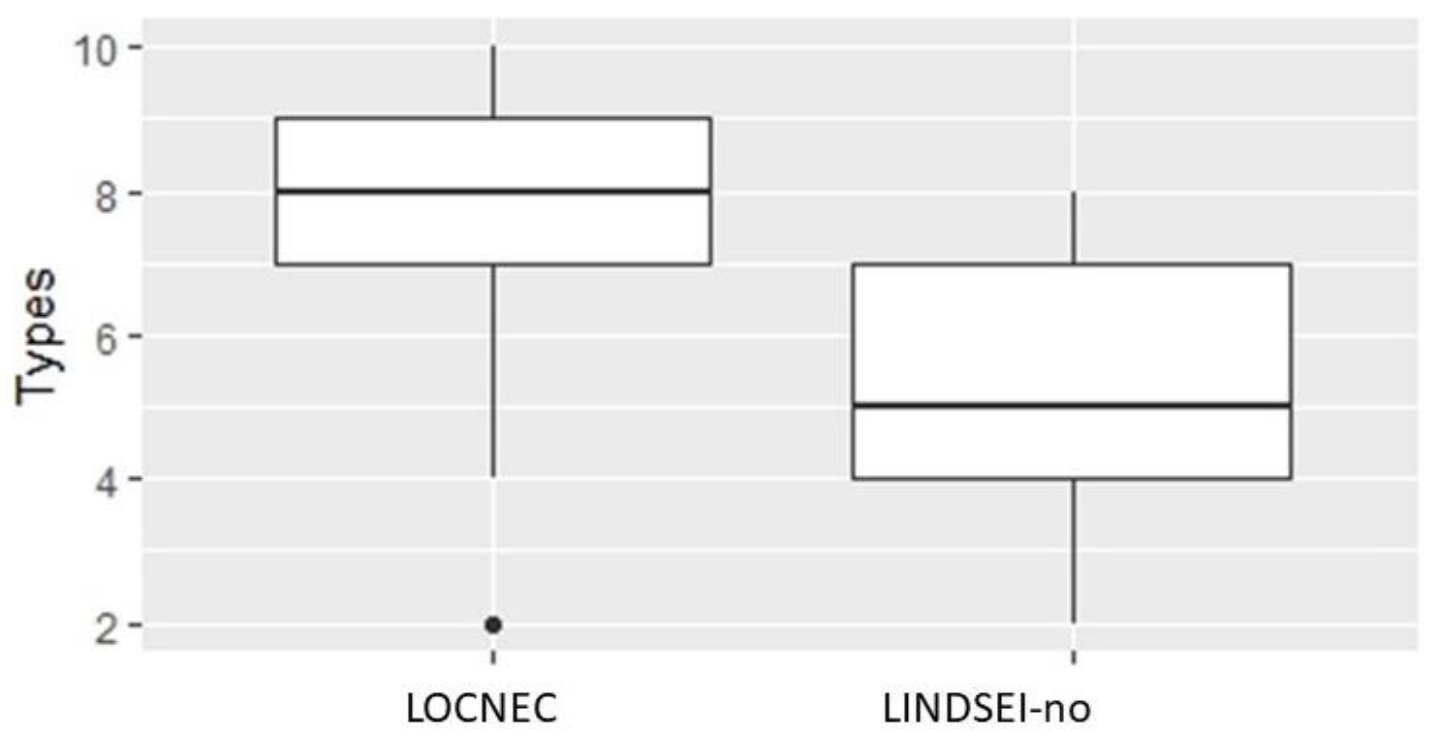

Figure 4 Total number of hedging strategies per speaker (types).

On average, the native speakers used approximately eight of the 10 expressions; the Norwegian learners used approximately five. However, as shown in Figure 4, there is some overlap between the native speaker range and the learner range. Norwegian learners in the outskirts of the third quartile overlap with native speakers in the first quartile. If the whiskers are taken into account, the native speaker plot covers an even larger part of the learner plot. This raises the question of whether a broader range of the Norwegian learners could be described as native-like users of hedging, if native-like is understood as 'what (any) native speakers do'. Figures 5-7 are examples of some of the most similar L1 and L2 profiles.

Figure 5 compares the hedging profiles of a learner and a native speaker, drawn from the upper part of the third quartile of the learner data and the lower part of the first quartile of the native speaker data. 


\section{Nordic Journal of Modern Language Methodology}

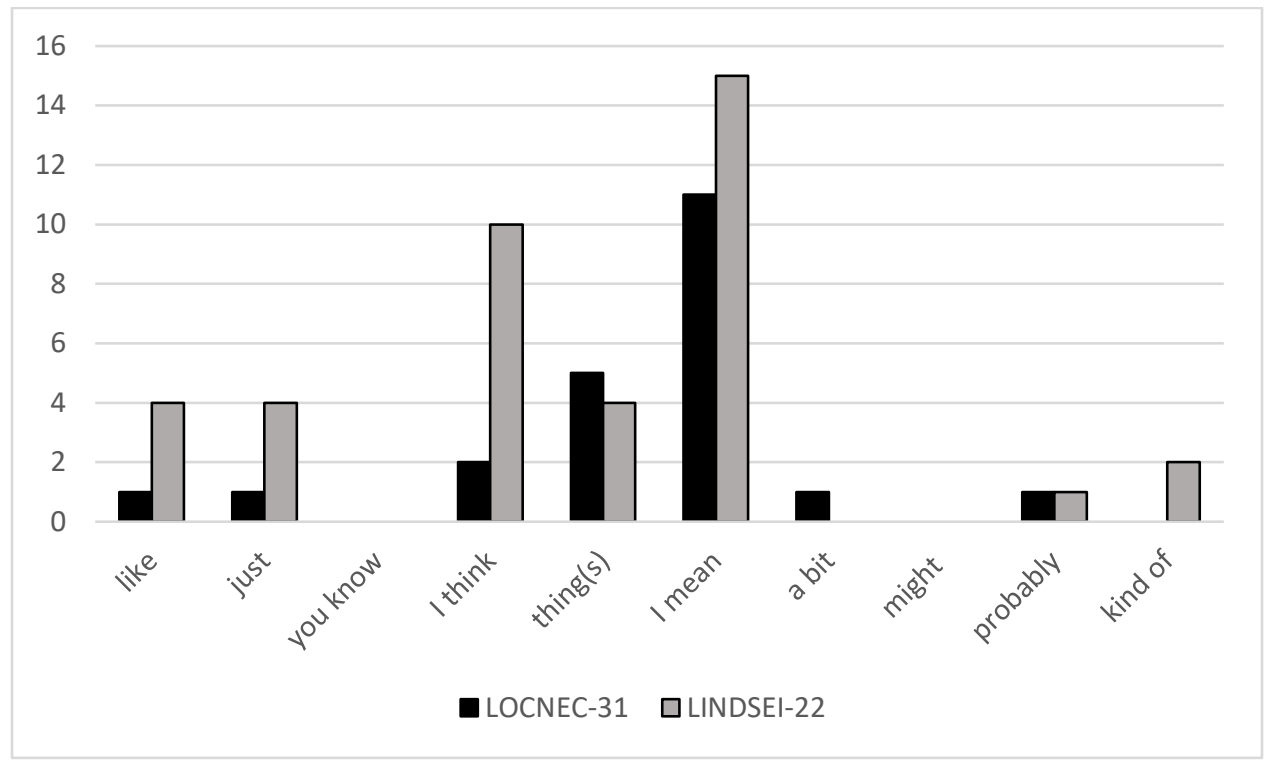

Figure 5 First example of a learner and native speaker profile.

Figure 5 is one example of similar native speaker and learner profiles. There were, however, several similar speaker profiles in the data. Figure 6 is another example of native and learner profiles that correspond to some degree.

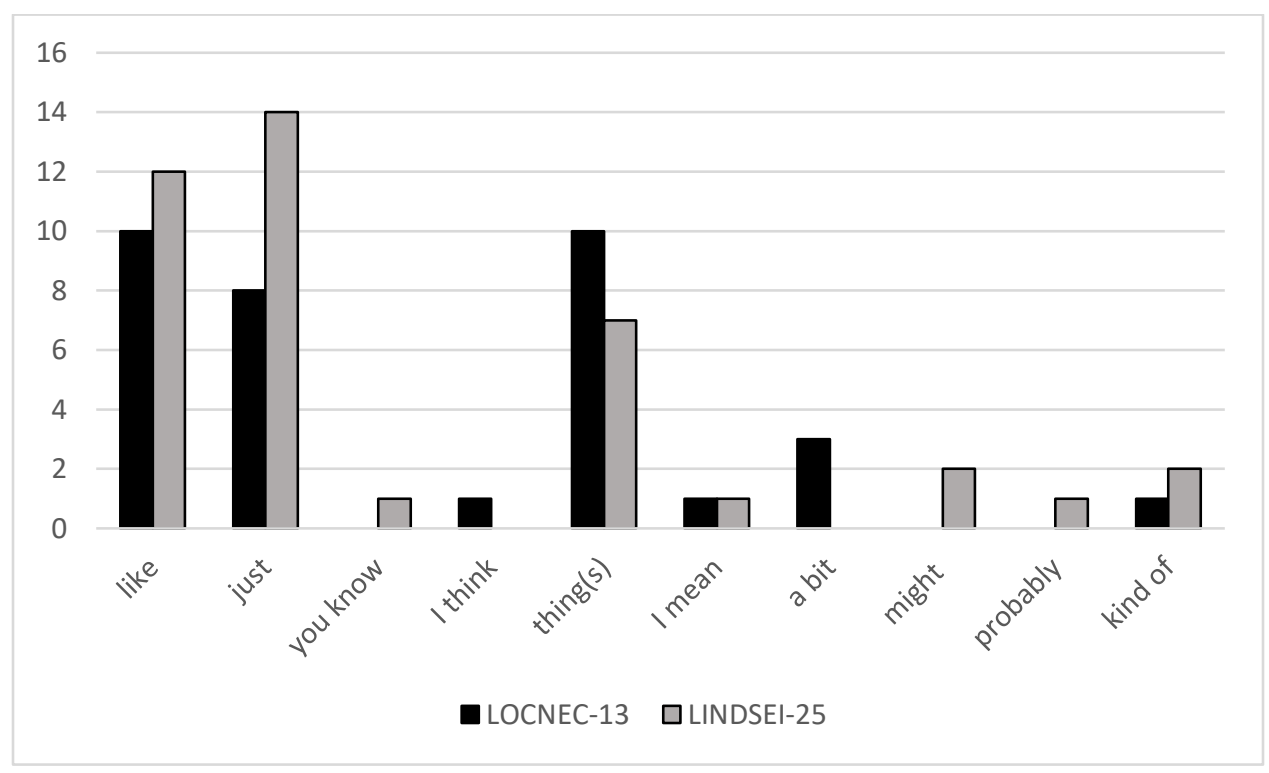

Figure 6 Second example of a learner and native speaker profile. 


\section{Nordic Journal of Modern Language Methodology}

Figure 4 also shows that there is great intra-speaker variation in both groups. Neither learners nor native speakers are homogenous groups. Learners are often characterised according to external factors, such as numbers of years of study, but such factors do not necessarily say anything about (variation in) their proficiency level. Furthermore, a low number of hedging strategies or a limited range of types does not necessarily indicate lack of mastery or activation; it could also be a matter of choice (Gablasova et al., 2017, 149). Some speakers in the native English material deviate from the majority, as illustrated in Figure 4. Although statistically, speakers such as the one indicated by the dot in Figure 4 are outliers, their use of hedging strategies will not necessarily be perceived as less native-like. Figure 7 illustrates the profiles of a native speaker outside the interquartile range and a learner with the same pattern. This example raises the question of whether learners should be perceived as non-native-like because they do not use all the hedging expressions or the same number of hedging expressions as the majority of native speakers.

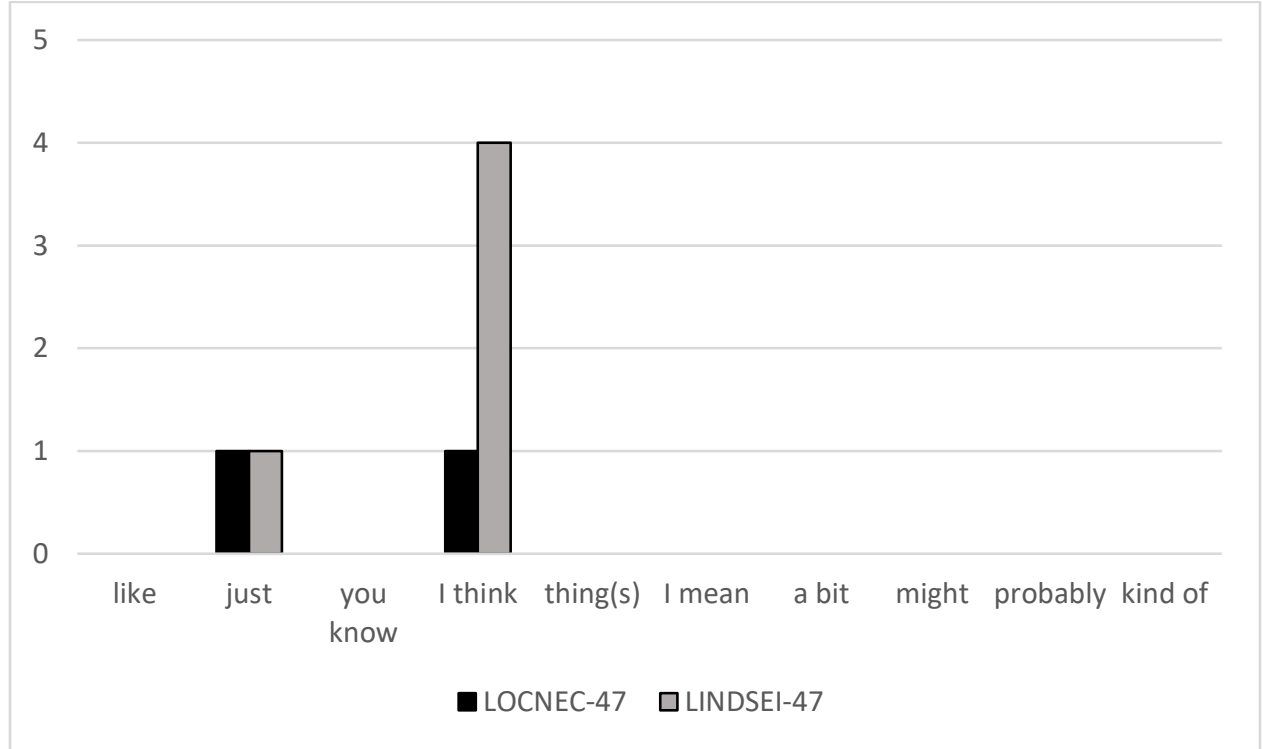

Figure 7 Third example of a learner and native speaker profile.

Section 4.2 shows that the Norwegian learners as a group used all 10 expressions and thus on the surface did not seem to use a more limited range of expressions. However, an overview of the total number of different types per speaker showed that Norwegian learners on average used 


\section{Nordic Journal of Modern Language Methodology}

fewer types of hedges than native English speakers. Still, the performance of the Norwegian learners overlapped with several of the native speakers.

\section{Concluding remarks}

This paper aimed to discover potential differences in the use of 10 hedging expressions by Norwegian advanced learners of English and native English speakers. Previous research has shown that learners tend to use both fewer and a more limited range of strategies. This has been proven for Norwegian learners at the lower secondary school level, but little was known about advanced learners of English.

The results indicate that although Norwegian advanced learners used fewer hedging strategies overall, this result was nuanced when the individual expressions and speakers were considered. Only five of the 10 expressions were used significantly more by native speakers, and $16 \%$ of the Norwegian learners were within the $75^{\text {th }}$ percentile of the English speakers in the total number of hedging strategies used per speaker. The results also showed a partial overlap of the number of types of strategies used, further nuancing the results. As a group, Norwegian advanced learners used fewer hedges (tokens) and hedging strategies (types), but individual variation within both language varieties complicates the picture.

These results contribute to our understanding of Norwegian advanced learners' pragmatic competence; however, they also raise some questions and red flags for future research. First, the study underlines the importance of looking at individual variation in the study of overand underuse. Drawing conclusions based on group-level data alone may give an incomplete picture of intervarietal differences. Second, it raises the question of what native-like hedging actually is. If the use of hedging strategies by a native speaker deviates from the majority of native speakers, will the speaker be perceived as non-native-like? 


\section{References}

Adolphs, S., \& Carter, R. (2013). Spoken corpus linguistics: From monomodal to multimodal (Vol. 15). New York: Routledge.

Aijmer, K. (1997). I think - An English modal particle. In T. Swan \& O. J. Westvik (Eds.), Modality in Germanic languages: Historical and comparative perspectives (pp. 1-47). Berlin: Mouton de Gruyter.

Aijmer, K. (2002). English discourse particles. Evidence from a corpus. Amsterdam, Philadelphia: Benjamins.

Aijmer, K., \& Rühlemann, C. (Eds.). (2015). Corpus pragmatics: A handbook. Cambridge: Cambridge University Press.

Baumgarten, N., \& House, J. (2010). I think and I don't know in English as lingua franca and native English discourse. Journal of Pragmatics, 42(5), 1184-1200. doi:10.1016/j.pragma.2009.09.018

Berthelin, S. R., \& Borthen, K. (2019). The semantics and pragmatics of Norwegian sentenceinternal jo. Nordic Journal of Linguistics, 42(1), 3-30.

De Cock, S. (2004). Preferred sequences of words in NS and NNS speech. Belgian Journal of English Language and Literatures (BELL) (New Series 2), 225-246.

Fraser, B. (2010). Pragmatic competence: The case of hedging. In G. Kaltenböck, W. Mihatsch, \& S. Schneider (Eds.), New approaches to hedging (pp. 15-34). UK: Bingley Emerald.

Friginal, E., Lee, J. J., Polat, B., \& Roberson, A. (2017). Hedging and boosting in EAP classroom discourse. In Exploring spoken English learner language using corpora: Learner talk (pp. 77-93). Cham: Springer International Publishing.

Gablasova, D., Brezina, V., \& McEnery, T. (2017). Exploring learner language through corpora: Comparing and interpreting corpus frequency information. Language Learning, 67, 130154. doi:10.1111/lang.12226

Gilquin, G., De Cock, S., \& Granger, S. (2010). Louvain International Database of Spoken English Interlanguage (CD-ROM + handbook). Louvain-la-Neuve: Presses Universitaires de Louvain.

Granger, S. (2015). Contrastive interlanguage analysis: A reappraisal. International Journal of Learner Corpus Research, 1(1), 7-24. doi: 10.1075/ijlcr.1.1.01gra

Gries, S. T. (2008). Dispersions and adjusted frequencies in corpora. International Journal of Corpus Linguistics, 13(4), 403-437. doi:10.1075/ijcl.13.4.02gri

Gries, S. T., \& David, C. V. (2007). This is kind of/sort of interesting: Variation in hedging in English. In P. Pahta, I. Taavitsainen, T. Nevalainen, \& J. Tyrkkö (Eds.), Towards multimedia in corpus linguistics. Helsinki: University of Helsinki.

Hasselgård, H., \& Johansson, S. (2011). Learner corpora and contrastive interlanguage analysis. In F. Meunier, S. De Cock, G. Gilquin, \& M. Paquot (Eds.), A taste for corpora. In honour of Sylviane Granger (pp. 33-62). Amsterdam: John Benjamins.

Hasselgreen, A. (2004). Testing the spoken English of young Norwegians: A study of test validity and the role of "smallwords" in contributing to pupils' fluency (Vol. 20). Cambridge: Cambridge University Press. 
Hasund, I. K. (2003). The discourse markers like in English and liksom in Norwegian teenage language: a corpus-based, cross-linguistic study. [Unpublished thesis]. University of Bergen / Agder University College, Bergen, Kristiansand.

Hasund, I. K., Opsahl, T., \& Svennevig, J. (2012). By three means: The pragmatic functions of three Norwegian quotatives. In I. Buchstaller \& I. van Alphen (Eds.), Quotatives: Crosslinguistic and cross-disciplinary perspectives (Vol. 15) (pp. 37-67). Amsterdam: John Benjamins.

Hinkel, E. (1997). Indirectness in L1 and L2 academic writing. Journal of Pragmatics, 27(3), 361-386. doi:10.1016/S0378-2166(96)00040-9

Holmes, J., Vine, B., \& Marra, M. (2020). Contesting the culture order: Contrastive pragmatics in action. Contrastive Pragmatics, 1, 1-27. https://doi.org/10.1163/26660393-12340002

Hyland, K. (1996). Writing without conviction? Hedging in science research articles. Applied Linguistics, 17(4), 433-454.

Hyland, K. (1998). Hedging in scientific research articles (Vol. 54). Amsterdam/Philadelphia: John Benjamins Publishing.

Johansen, S. H. (2020). "I guess anyone would do that wouldn't they?" How do native speakers of Norwegian and English hedge in informal conversations?. Languages in Contrast. https://doi.org/10.1075/lic.19025.joh

Kaltenböck, G., Mihatsch, W., \& Schneider, S. (Eds.). (2010). New approaches to hedging (Vol. 9). UK: Emerald Bingley.

Kärkkäinen, E. (1990). Modality as a strategy in spoken interaction [Unpublished thesis]. University of Oulu, Oulu.

Kasper, G. (1979). Communication strategies: Modality reduction. The Interlanguage Studies Bulletin, 4(1), 266-283.

Kay, P. (1997). Words and the grammar of context. Stanford California: CSLI Publications.

Love, R., Dembry, C., Hardie, A., Brezina, V., \& McEnery, T. (2017). The spoken BNC2014. International Journal of Corpus Linguistics, 22(3), 319-344. doi:10.1075/ijcl.22.3.02lov

Neary-Sundquist, C. (2013). The use of hedges in the speech of ESL learners. Elia, 13(1), 149174.

Nikula, T. (1997). Interlanguage view on hedging. In R. Markkanen \& H. Schröder (Eds.), Hedging and discourse approaches to the analysis of a pragmatic phenomenon in academic texts (pp. 188-207). Berlin / New York: Walter de Gruyter.

Opsahl, T., \& Svennevig, J. (2007). Må ha det. Bare må ha det: Bare som pragmatisk partikkel i samtale. Norsk Lingvistisk Tidsskrift (25), 29-55.

Paquot, M., \& Plonsky, L. (2017). Quantitative research methods and study quality in learner corpus research. International Journal of Learner Corpus Research, 3(1), 61-94. https://doi.org/10.1075/ijlcr.3.1.03paq

Romero-Trillo, J. (2002). The pragmatic fossilization of discourse markers in non-native speakers of English. Journal of Pragmatics, 34(6), 769-784. https://doi.org/10.1016/S03782166(02)00022-X

Romero-Trillo, J. (2018). Corpus pragmatics and second language pragmatics: A mutualistic entente in theory and practice. International Journal of Corpus Linguistics and Pragmatics, 2(2), 113-127. doi:10.1007/s41701-018-0031-5 


\section{Nordic Journal of Modern Language Methodology}

Sandal, K. L. (2016). "And, like, they said ... well, you know”: A corpus-based study of the discourse markers 'like', 'well' and 'you know' in spoken Norwegian learner language and British English. [Unpublished Master thesis]. University of Oslo, Oslo.

Scott, M. (2016). WordSmith tools (Version 7). Lexical Analysis Software.

Šeškauskienè, I. (2008). Hedging in ESL: A case study of Lithuanian learners. Kalbu Studijos (13), 71-76.

Thomson, J. J. (2016). Hedging in year nine girls' and boys' written English in Norwegian schools. [Unpublished Master thesis]. University of Stavanger, Norway.

Ventola, E., \& Mauranen, A. (1990). Tutkijat ja englanniski kirjoittaminen [Researchers and writing in English]. Helsinki: Yliopistopaino. 